\title{
Is Professionalism Important in Physician Assistant Education?
}

Susan Ryan

sr990@nova.edu

Follow this and additional works at: https://nsuworks.nova.edu/ijahsp

Part of the Education Commons, and the Medicine and Health Sciences Commons

\section{Recommended Citation}

Ryan S. Is Professionalism Important in Physician Assistant Education?. The Internet Journal of Allied Health Sciences and Practice. 2016 Jan 01;14(2), Article 11.

This Manuscript is brought to you for free and open access by the College of Health Care Sciences at NSUWorks. It has been accepted for inclusion in Internet Journal of Allied Health Sciences and Practice by an authorized editor of NSUWorks. For more information, please contact nsuworks@nova.edu. 


\title{
Is Professionalism Important in Physician Assistant Education?
}

\begin{abstract}
Purpose: This study was designed to demonstrate the importance of a formal professionalism curriculum in physician assistant (PA) education. The PA concept arose from the medical profession, and PA education was designed to follow the medical model of education. Courses have been mandated by the Accreditation Council for Graduate Medical Education (ACGME) to include professionalism. Just as in the curriculum in medical schools, PA educators have been allowed to create their own professionalism curricula. The American Academy of Physician Assistants (AAPA) and the Accreditation Review Commission on Education for the Physician Assistant (ARC-PA) have mandated that professionalism and ethics must be included in PA education. To address this need, a professionalism curriculum for first year PA students was created that combined standards of professionalism that are taught in medical school with those from the PA profession. Method: Sixty-four students enrolled in their first year of a master's degree PA program were asked to voluntarily participate in a two-part survey to assess their knowledge of professionalism. The initial survey was administered prior to any formal education in professionalism. The same survey was repeated following the completion of the professionalism curriculum. The design of the survey was cross sectional and consisted of close ended questions. A Likert scale was utilized for responses, allowing for statistical analysis and comparison. Results: Sixty-three of 64 students completed both surveys. Results did not demonstrate a statistically significant improvement in knowledge of professionalism. Student evaluations were overwhelmingly positive, as was their participation in group discussions. Conclusions: Professionalism did not significantly improve. The lack of statistical significance may have referred to the lack of reliability in the findings but did not indicate the curriculum was effective or ineffective. It may have been wiser to continue professionalism education throughout the didactic year, incorporating case studies and simulation exercises.
\end{abstract}

\section{Author Bio(s)}

Susan Ryan, Ed.D., PA-C is the Clinical Coordinator in the Physician Assistant Program at Adventist University in Orlando, FL.. 


\title{
IJAHSP \\ The Internet Joưnal of Allied Health Sciences and Practice
}

Dedicated to allied health professional practice and education

Vol. 14 No. 2 ISSN 1540-580X

\section{Is Professionalism Important in Physician Assistant Education?}

\author{
Susan Ryan, EdD, PA-C \\ Adventist University \\ United States
}

\begin{abstract}
Purpose: This study was designed to demonstrate the importance of a formal professionalism curriculum in physician assistant (PA) education. The PA concept arose from the medical profession, and PA education was designed to follow the medical model of education. Courses have been mandated by the Accreditation Council for Graduate Medical Education (ACGME) to include professionalism. Just as in the curriculum in medical schools, PA educators have been allowed to create their own professionalism curricula. The American Academy of Physician Assistants (AAPA) and the Accreditation Review Commission on Education for the Physician Assistant (ARC-PA) have mandated that professionalism and ethics must be included in PA education. To address this need, a professionalism curriculum for first year PA students was created that combined standards of professionalism that are taught in medical school with those from the PA profession. Method: Sixty-four students enrolled in their first year of a master's degree PA program were asked to voluntarily participate in a two-part survey to assess their knowledge of professionalism. The initial survey was administered prior to any formal education in professionalism. The same survey was repeated following the completion of the professionalism curriculum. The design of the survey was cross sectional and consisted of close ended questions. A Likert scale was utilized for responses, allowing for statistical analysis and comparison. Results: Sixty-three of 64 students completed both surveys. Results did not demonstrate a statistically significant improvement in knowledge of professionalism. Student evaluations were overwhelmingly positive, as was their participation in group discussions. Conclusions: Professionalism did not significantly improve. The lack of statistical significance may have referred to the lack of reliability in the findings but did not indicate the curriculum was effective or ineffective. It may have been wiser to continue professionalism education throughout the didactic year, incorporating case studies and simulation exercises.
\end{abstract}

\section{INTRODUCTION}

The American Academy of Physician Assistants (AAPA) notes that instruction in ethics must be included in PA education. ${ }^{1}$ The Accreditation Review Commission on Education for the Physician Assistant (ARC-PA) mandates the inclusion of professionalism in the PA curriculum. Section B1.05 states "the curriculum must include instruction about intellectual honesty and appropriate academic and professional conduct." In addition, section B2.16 notes "the program curriculum must include instruction in the principles and practice of medical ethic."2 This allows each individual PA program to establish its own curriculum design for medical ethics and professionalism courses.

Many physician assistant (PA) students graduating from accredited educational programs may lack a solid understanding of the concept of professionalism. The lack of formal knowledge about professionalism and its significance in health care delivery and patient interaction can create confusion for PA students as they transition from student to practicing clinician. The growth and daily intrusion of social media has also added to the confusion. The emergence of technology and managed care have created additional challenges. Recent literature has identified that the lack of standardized education in professionalism in PA education may be a causative factor. Doscher discussed the effects on patient confidentiality and potential liability created with the increased use of social media. ${ }^{3}$ Doscher noted that the AAPA Professional Practice Council believed this could be alleviated with increased attention to ethics. Additionally, Roe noted several cases in which inappropriate use of social media resulted in disciplinary actions. ${ }^{4}$ These actions were not deemed acceptable in accordance with the standards of conduct advocated by the Guidelines for Ethical Conduct for the Physician Assistant Profession. ${ }^{5}$ Hooker and Cawley discussed the use of the medical model as the basis of PA education. ${ }^{6}$ Therefore, utilizing standards of medical professionalism education can be adopted in PA professionalism education.

(C) The Internet Journal of Allied Health Sciences and Practice, 2016 
In 2004, Papadakis et al examined the relationship between medical students with documented episodes of unprofessional behavior in medical school and subsequent disciplinary action by state medical boards ${ }^{7}$ The results revealed that 65 of 68 of previously disciplined physicians had been admonished for violations of professionalism by their respective state boards of medicine. This demonstrated the importance of identifying lapses in professionalism early on.

Research focused upon medical education as a source of, and answer to, the problem. The common theme was found to be the loss of professionalism among physicians. In 1992, curriculum specifically devoted to professionalism was mandated to be included in medical education. ${ }^{8}$

A collaborative effort between the American Board of Internal Medicine (ABIM), the American College of Physicians Foundation, and the European Federation of Internal Medicine resulted in a guide entitled Medical Professionalism in the New Millennium: A Physician Charter in 2002. The Charter defines professionalism as the foundation of medicine's contract with society. It outlined three fundamental principles: patient welfare, patient autonomy, and social justice. It also clearly defined professional responsibilities. These include: commitment to professional competence; honesty; patient confidentiality; maintenance of appropriate relationships; improving quality of care; improving access to care; fair distribution of finite resources; maintenance of competence in education; professional responsibilities; and avoidance of conflicts of interest. ${ }^{9}$

The effect of the above events demonstrated professionalism as a complex process that must adapt and evolve according to the demands placed upon health care providers in changing situations. ${ }^{10}$ In the past, professionalism had been thought of as innate character traits. Now, professionalism was considered something that could be taught.

The purpose of this study was to assess the effect of educating first year students in a PA program about professionalism. Assessments were made by comparing results before professionalism education (pre-survey) with results after professionalism education (post-survey). A professionalism curriculum was created and taught in the first semester with a two hour segment solely devoted to professionalism. Medical Professionalism in the New Millennium: A Physician Charter and the American Medical Association's Declaration of Professional Responsibility: Medicine's Social Contract with Humanity were used as a foundation. ${ }^{12}$ The PA Code of Ethics provided additional framework and specificity to the PA profession. Curriculum was taught utilizing lectures and focus group discussions about specific topics relating to professionalism

\section{Methods}

The study design involved use of a survey. A nonprobability sample using convenience sampling was utilized. In addition, an anonymous course evaluation was completed by each student at the conclusion of the semester. The course evaluation is administered by the university upon completion of the curriculum. Results are averaged and provided to instructors after the semester officially ends.

\section{Study Participants}

Sixty-four first year students enrolled in a master's degree PA program were voluntarily asked to complete the surveys. Sixty-four students (17 males, 47 females) completed the pre-instruction survey. Sixty-three students (17 males, 46 females) completed the post-instruction survey. Mean age of the students was 26 years. Seven students had obtained a B.A. degree, 53 obtained a B.S. degree, and four other students listed other as their highest degree. Three students were not U.S. citizens, 60 were U.S. citizens, and one had dual citizenship. All but four of the students reported having previous health care experience prior to entering PA school.

\section{Survey}

The survey utilized was developed at Penn State University. ${ }^{11}$ It had been validated for use as a tool to measure attitudes towards professionalism among medical students, residents, and faculty. Written permission was obtained. The survey encompassed 36 items that were categorized into six factors of professionalism: accountability, altruism, excellence, duty, honor and integrity, and respect for others. This study was chosen as these six factors echoed the six elements of professionalism defined by the ABIM Charter on Professionalism.

Construct validity was obtained by using Kaiser's Criterion, identifying seven factors with eight values greater than 1.0. Results were compared with the six elements noted in the ABIM Charter on professionalism. Internal consistency and reliability were obtained through use of Cronbach's alpha. Cronbach's alpha is often used with multiple Likert questions in a survey to measure internal reliability. Acceptable levels should be 0.70 or greater to ensure effectiveness. Six of the seven scales had reliability estimates ranging from 0.71 to 0.78 . The scales for Respect contained only two items, providing a reliability estimate of 0.51 .

(c) The Internet Journal of Allied Health Sciences and Practice, 2016 
The wording of several questions was changed from physician to physician assistant to make them appropriate for the PA students. Several fellow faculty members agreed to pilot test the survey. They reviewed questions for ease of use, clarity, and appropriateness to the topic.

\section{Procedures}

Approval was obtained from the university's institutional review board. Per university protocol, a participation letter was created and made accessible for all students to read. Participation was voluntary and anonymous. Another faculty member discussed the purpose of the survey and reviewed the letter of participation with the students. The survey was printed out and placed in a box prior to the start of class. Participating students took a copy of the survey, completed it, and returned it to the box. The box was collected by that faculty member after 20 minutes and given to the author of the study. This procedure was repeated twice, once before the official start of the course and again after completion of the course. The professor providing the instruction manually tabulated all results.

Curriculum objectives included the history of the PA profession, the role of the PA in health care, current legal and political issues relating to PA practice, PA organizations, and the role of professionalism. The lecture on professionalism focused on both organizational and personal aspects of professionalism. All topics referenced the six elements of professionalism outlined in the ABIM Charter throughout the course. The Guidelines for Ethical Conduct for the PA were also utilized in discussions. Students were divided into focus groups and analyzed peer-reviewed articles or case studies after specific topics were discussed in class. Written responses by each group were discussed, analyzing for common themes in accordance with the six elements of professionalism.

\section{Statistical Analysis}

Pre-survey and post-survey results were tallied by the author. Likert choices included: Never, Little, Some, Much, or Great Deal. Each Likert choice was assigned a point value. Never had a point value of 1; Little had a point value of 2; Some had a point value of 3; Much had a point value of 4; and Great Deal had a point value of 5 . The number of responses to each answer was multiplied by the corresponding point value to create a specific point value. For example, using question \#9 in Altruism from the table below, there were 2 responses for choice Some. Some had a point value of 3 , so 3 points multiplied by 2 responses equals a total of 6 points. Much had 16 responses with a point value of 4 , so $4 \times 16=64$, etc. The sum (the number in parentheses) was totaled per question and expressed as "Points." For example, the total number of points for question \#9 was 300 , the total number for question \#12 was 271 , etc., and these points were added together for a Grand Total number. In this manner, direct comparisons could be noted between pre- and post-surveys by comparing the total points of each question as well as the Grand Totals of each specific category. Comparing the numbers also provides a means of comparison between pre-instruction and post-instruction surveys. An example of the category altruism is shown below.

\begin{tabular}{|c|c|c|c|c|c|c|}
\hline \multicolumn{7}{|c|}{ Altruism Pre-survey Results } \\
\hline Question \# & Never & Little & Some & Much & Great Deal & Points \\
\hline 9 & 0 & 0 & $2(6)$ & $16(64)$ & $46(230)$ & 300 \\
\hline 12 & 0 & 0 & $12(36)$ & $25(100)$ & $27(135)$ & 271 \\
\hline 20 & 0 & $2(4)$ & $10(30)$ & $26(104)$ & $26(130)$ & 266 \\
\hline 24 & 0 & 0 & $4(12)$ & $17(68)$ & $43(215)$ & 295 \\
\hline 37 & 0 & 0 & $3(9)$ & $19(76)$ & $42(210)$ & 295 \\
\hline 38 & 0 & $1(2)$ & $5(15)$ & $17(68)$ & $41(205)$ & 290 \\
\hline Grand Total & & & & & & 1,717 \\
\hline
\end{tabular}

Altruism Post-survey Results

\begin{tabular}{|c|c|c|c|c|c|c|}
\hline Question \# & Never & Little & Some & Much & Great Deal & Points \\
\hline 9 & 0 & 0 & $1(3)$ & $12(48)$ & $51(255)$ & 306 \\
\hline 12 & 0 & $2(4)$ & $5(15)$ & $22(88)$ & $34(170)$ & 277 \\
\hline 20 & 0 & $3(6)$ & $5(15)$ & $17(68)$ & $38(190)$ & 279 \\
\hline 24 & 0 & 0 & $2(6)$ & $9(36)$ & $32(160)$ & 202 \\
\hline 37 & 0 & 0 & $4(12)$ & $7(28)$ & $32(260)$ & 200 \\
\hline 38 & 0 & 0 & $1(3)$ & $10(40)$ & $52(260)$ & 303 \\
\hline Grand Total & & & & & & 1,567 \\
\hline
\end{tabular}

(c) The Internet Journal of Allied Health Sciences and Practice, 2016 
The remaining categories of professionalism -- accountability, excellence, duty, honor and integrity, and respect were tallied up in the same manner as shown below.

Accountability Pre-survey Results

\begin{tabular}{|c|c|c|c|c|c|c|}
\hline Question \# & Never & Little & Some & Much & Great Deal & Points \\
\hline 7 & 0 & $3(6)$ & $15(45)$ & $27(108)$ & $18(90)$ & 249 \\
\hline 17 & 0 & $1(2)$ & $5(15)$ & $12(48)$ & $45(225)$ & 290 \\
\hline 23 & 0 & $1(2)$ & $14(42)$ & $27(108)$ & $21(105)$ & 257 \\
\hline 29 & 0 & 0 & $3(9)$ & $18(72)$ & $42(210)$ & 291 \\
\hline 30 & 0 & 0 & $3(9)$ & $15(60)$ & $45(225)$ & 294 \\
\hline 36 & 0 & 0 & 0 & $8(32)$ & $55(275)$ & 315 \\
\hline Grand Total & & & & & & 1696 \\
\hline
\end{tabular}

Accountability Post-survey Results

\begin{tabular}{|c|c|c|c|c|c|c|}
\hline Question \# & Never & Little & Some & Much & Great Deal & Points \\
\hline 7 & 0 & $4(8)$ & $12(36)$ & $25(100)$ & $22(110)$ & 254 \\
\hline 17 & $1(1)$ & 0 & $1(3)$ & $8(32)$ & $53(265)$ & 301 \\
\hline 23 & 0 & $4(8)$ & $4(12)$ & $22(88)$ & $33(165)$ & 273 \\
\hline 29 & 0 & $1(2)$ & $1(3)$ & $11(44)$ & $48(240)$ & 299 \\
\hline 30 & 0 & $2(4)$ & $2(6)$ & $11(44)$ & $48(240)$ & 294 \\
\hline 36 & 0 & 0 & $1(3)$ & $7(28)$ & $55(275)$ & 306 \\
\hline Grand Total & & & & & & 1727 \\
\hline
\end{tabular}

\begin{tabular}{|c|c|c|c|c|c|c|}
\hline \multicolumn{7}{|c|}{ Excellence Pre-survey Results } \\
\hline Question \# & Never & Little & Some & Much & Great Deal & Points \\
\hline 8 & 0 & $1(2)$ & $3(9)$ & $31(124)$ & $29(145)$ & 280 \\
\hline 13 & 0 & 0 & $11(33)$ & $18(72)$ & $35(175)$ & 280 \\
\hline 21 & 0 & 0 & 0 & $14(56)$ & $50(250)$ & 306 \\
\hline 25 & 0 & 0 & $4(12)$ & $22(88)$ & $38(190)$ & 290 \\
\hline 31 & 0 & $1(2)$ & $7(21)$ & $20(80)$ & $36(180)$ & 283 \\
\hline 35 & 0 & $2(4)$ & $8(24)$ & $30(120)$ & $24(120)$ & 268 \\
\hline Grand Total & & & & & & 1707 \\
\hline
\end{tabular}

\begin{tabular}{|c|c|c|c|c|c|c|}
\hline \multicolumn{7}{|c|}{ Excellence Post-survey Results } \\
\hline Question \# & Never & Little & Some & Much & Great Deal & Points \\
\hline 8 & 0 & 0 & $4(12)$ & $20(80)$ & $39(195)$ & 287 \\
\hline 13 & 0 & $1(2)$ & $6(18)$ & $22(88)$ & $34(170)$ & 278 \\
\hline 21 & 0 & 0 & $2(6)$ & $11(44)$ & $50(250)$ & 300 \\
\hline 25 & 0 & $2(4)$ & $1(3)$ & $16(64)$ & $44(220)$ & 291 \\
\hline 31 & $1(1)$ & $1(2)$ & $3(9)$ & $14(56)$ & $44(220)$ & 287 \\
\hline 35 & 0 & $2(4)$ & $6(18)$ & $20(80)$ & $35(175)$ & 277 \\
\hline Grand Total & & & & & & 1720 \\
\hline
\end{tabular}


Duty Pre-survey Results

\begin{tabular}{|c|c|c|c|c|c|c|}
\hline Question \# & Never & Little & Some & Much & Great Deal & Points \\
\hline 10 & 0 & 0 & $1(3)$ & $12(48)$ & $51(255)$ & 306 \\
\hline 16 & 0 & $3(6)$ & $22(66)$ & $20(80)$ & $19(95)$ & 247 \\
\hline 18 & $1(1)$ & $6(12)$ & $17(51)$ & $22(88)$ & $18(90)$ & 242 \\
\hline 28 & $1(1)$ & $3(6)$ & $9(27)$ & $16(64)$ & $35(175)$ & 273 \\
\hline 32 & 0 & $4(8)$ & $4(12)$ & $17(68)$ & $39(195)$ & 283 \\
\hline 39 & $2(2)$ & $1(2)$ & $5(150$ & $19(76)$ & $37(185)$ & 280 \\
\hline Grand Total & & & & & & 1631 \\
\hline
\end{tabular}

\begin{tabular}{|c|c|c|c|c|c|c|}
\hline \multicolumn{7}{|c|}{ Duty Post-survey Results } \\
\hline Question \# & Never & Little & Some & Much & Great Deal & Points \\
\hline 10 & 0 & 0 & 0 & $7(28)$ & $56(280)$ & 308 \\
\hline 16 & $1(1)$ & $6(12)$ & $9(27)$ & $31(124)$ & $16(80)$ & 244 \\
\hline 18 & $2(2)$ & $3(6)$ & $6(18)$ & $30(120)$ & $22(110)$ & 256 \\
\hline 28 & 0 & $2(4)$ & $7(21)$ & $16(64)$ & $38(190)$ & 279 \\
\hline 32 & 0 & $3(6)$ & $4(12)$ & $11(44)$ & $45(225)$ & 287 \\
\hline 39 & 0 & 0 & $2(6)$ & $20(80)$ & $41(205)$ & 291 \\
\hline Grand Total & & & & & & 1665 \\
\hline
\end{tabular}

\begin{tabular}{|c|c|c|c|c|c|c|}
\hline \multicolumn{7}{c}{ Honor and Integrity Pre-survey Results } \\
\hline Question \# & Never & Little & Some & Much & Great Deal & Points \\
\hline 6 & 0 & $1(2)$ & $4(12)$ & $8(32)$ & $51(255)$ & 301 \\
\hline 14 & 0 & 0 & $1(3)$ & $15(60)$ & $48(240)$ & 303 \\
\hline 19 & 0 & 0 & $5(15)$ & $20(80)$ & $39(195)$ & 290 \\
\hline 26 & 0 & $2(4)$ & $8(24)$ & $18(72)$ & $36(180)$ & 280 \\
\hline 33 & 0 & 0 & $2(6)$ & $13(52)$ & $50(250)$ & 308 \\
\hline 41 & 0 & 0 & $2(6)$ & $17(68)$ & $45(225)$ & 299 \\
\hline Grand Total & & & & & & 1781 \\
\hline
\end{tabular}

\begin{tabular}{|c|c|c|c|c|c|c|}
\hline \multicolumn{7}{c|}{ Honor and Integrity Post-survey Results } \\
\hline Question \# & Never & Little & Some & Much & Great Deal & Points \\
\hline 6 & 0 & 0 & 0 & $3(12)$ & $60(300)$ & 312 \\
\hline 14 & 0 & 0 & 0 & $10(40)$ & $53(265)$ & 305 \\
\hline 19 & 0 & $1(2)$ & $1(3)$ & $11(44)$ & $50(250)$ & 299 \\
\hline 26 & 0 & $2(4)$ & $6(18)$ & $14(56)$ & $41(205)$ & 283 \\
\hline 33 & 0 & 0 & 0 & $13(52)$ & $50(250)$ & 302 \\
\hline 41 & 0 & 0 & $2(6)$ & $13(52)$ & $48(240)$ & 298 \\
\hline Grand Total & \multicolumn{7}{l|l}{} & & & 1800 \\
\hline
\end{tabular}

\begin{tabular}{|c|c|c|c|c|c|c|}
\hline \multicolumn{7}{c|}{ Respect Pre-survey Results } \\
\hline Question \# & Never & Little & Some & Much & Great Deal & Points \\
\hline 11 & 0 & 0 & $2(6)$ & $19(76)$ & $43(215)$ & 297 \\
\hline 15 & 0 & 0 & $2(6)$ & $12(48)$ & $50(250)$ & 304 \\
\hline 22 & 0 & 0 & $1(3)$ & $11(44)$ & $52(260)$ & 307 \\
\hline 27 & 0 & 0 & $1(3)$ & $14(56)$ & $49(245)$ & 304 \\
\hline 34 & 0 & $1(2)$ & $2(6)$ & $18(72)$ & $43(215)$ & 295 \\
\hline 40 & 0 & $2(4)$ & $1(3)$ & $16(64)$ & $45(225)$ & 296 \\
\hline Grand Total & & & & & & 1803 \\
\hline
\end{tabular}


Respect Post-survey Results

\begin{tabular}{|c|c|c|c|c|c|c|}
\hline Question \# & Never & Little & Some & Much & Great Deal & Points \\
\hline 11 & 0 & 0 & $1(3)$ & $16(64)$ & $46(230)$ & 297 \\
\hline 15 & 0 & 0 & $1(3)$ & $8(32)$ & $54(270)$ & 305 \\
\hline 22 & 0 & 0 & $1(3)$ & $12(48)$ & $50(250)$ & 301 \\
\hline 27 & 0 & $2(4)$ & 0 & $10(40)$ & $51(255)$ & 299 \\
\hline 34 & 0 & 0 & $5(15)$ & $11(44)$ & $47(235)$ & 294 \\
\hline 40 & 0 & 0 & 0 & $17(68)$ & $46(230)$ & 298 \\
\hline Grand Total & & & & & & 1794 \\
\hline
\end{tabular}

There was a difference in the numbers of voluntary responses in the pre-instruction survey (64) and the post-instruction survey (63). Due to the anonymity of the survey, no response could be excluded. In order to adjust for this, the pre-survey results were multiplied by 0.984 (63 divided by 64). This was done for all six pre-survey categories. For example, the pre-survey results for Altruism were 1,717 . Multiplying 1,717 by 0.984 yields $1,689.528(1,689)$. The adjusted values for all pre-survey result categories are shown below.

\begin{tabular}{|c|c|c|}
\hline \multicolumn{3}{|c|}{ Adjusted Values for Presurvey Results } \\
\hline Category & Presurvey Results & Adjusted Results \\
\hline Altruism & 1717 & 1689 \\
\hline Accountability & 1696 & 1668 \\
\hline Excellence & 1707 & 1680 \\
\hline Duty & 1631 & 1605 \\
\hline Honor \& Integrity & 1781 & 1781 \\
\hline Respect & 1803 & 1773 \\
\hline
\end{tabular}

\section{Results}

Finally, a Two-Tailed t-Test was performed using SPSS software to compare the adjusted pre-survey results with post-survey results. Results of the final comparisons and statistical significance are shown below.

\begin{tabular}{|c|c|c|c|c|}
\hline \multicolumn{7}{|c}{ Comparison Results of Pre-survey and Post-survey } \\
\hline Category & $\begin{array}{c}\text { Presurvey } \\
\text { Grand Total }\end{array}$ & $\begin{array}{c}\text { Postsurvey Grand } \\
\text { Total }\end{array}$ & Test results & Significance \\
\hline Altruism & 1689 & 1567 & 0.359 & not significant \\
\hline Accountability & 1668 & 1727 & 0.465 & not significant \\
\hline Excellence & 1680 & 1720 & 0.305 & not significant \\
\hline Duty & 1605 & 1665 & 0.480 & not significant \\
\hline Honor \& Integrity & 1781 & 1799 & 0.271 & not significant \\
\hline Respect & 1773 & 1794 & 0.207 & not significant \\
\hline
\end{tabular}

Post-instruction Evaluation by Students. Grading choices run from zero to 4.

Course Evaluation:

Organization -3.73

Relevance -3.73

Activities -3.67

Grading -3.71

Resources -3.70

Instructor Evaluation:

Preparation -3.81

Presentation -3.78

Assessment -3.75

Interaction -3.78 


\section{Discussion}

PA students are expected to assume the role of health care provider upon graduation and entry into medicine. Initially, students rely upon learned personal values when confronted with ethical dilemmas. Next, students rely upon behavior learned from role models. Incorporating critical thinking processes is essential to aid in solving clinical problems. The evaluation and analytic skills parts of critical thinking allow students to exceed their personal values and role modeling, thereby incorporating professional and ethical principles. ${ }^{13}$

Another study noted that while medical students entering school are idealistic, they lack a clear understanding of the values and characteristics that define medical professionalism. Medical educators are responsible for ensuring that learning environments promote the core values of professionalism. They are also responsible for providing students with the skills to uphold them when challenged. ${ }^{14}$

Professionalism is expressed on two levels - at an individual level to patients, and at a societal level. Health care educators have a responsibility to demonstrate how to adapt the core values of professionalism to contemporary reality. The effects of rapidly changing technology and the use of digital media can overwhelm students at they try to behave professionally. ${ }^{15}$ The impact of social media and the loss of professionalism cannot be ignored. Health care personnel use social media to speak with colleagues and the public. The dangers of inappropriate use of social media have resulted in damage to public and professional personalities alike. Lawsuits, monetary fines, public censure, loss of licensure, and loss of employment have occurred. PAs also represent the organization in which they are employed. PAs must understand the possible liabilities of "friending" patients, employers, or coworkers. ${ }^{16}$ Attorneys Herrin and Ingram discussed how "friending" a patient, either as part of a corporation or as an individual provider, may result in violations of the Health Insurance Portability and Accountability Act (HIPAA). ${ }^{17}$

The majority of students entering PA school are in their early 20s. Most have just graduated from a baccalaureate program. It is important to note that students who have not yet worked as health care providers often have very little experience with the importance of ethics and professionalism in everyday patient encounters. They may also lack coping skills. However, they have the academic ability and social skills to learn appropriate ethical and professional behaviors. It is essential in the learning process for PA faculty to develop a professional, collaborative relationship for students to model. Evaluating an applicant's maturity level is also critical. ${ }^{18}$

The PA role is unique as PAs are the only professionals licensed to practice medicine under the auspices of a supervising physician. Therefore, they not only represent themselves but also the physicians and the institution employing them. The PA/MD relationship is built upon mutual trust and respect.

The significant demands of PA training may also result in academic dishonesty. Literature shows that those who cheat once are more likely to cheat in work settings. Students may fail to realize that didactic cheating not only harms them as they have a weakened knowledge base, but also that clinical cheating may result in increased expense to the patient. Additionally, while cheating should be treated as a serious offense, all persons who witnessed the cheating also have a responsibility to report the event. ${ }^{19}$

The final comparison of results demonstrated a significance value of less than 0.5 , which implies a lack of statistical significance. No significant improvement in PA students' knowledge was observed after receiving instruction in professionalism. This was the opposite of the expected and desired results.

The lack of statistical significance may suggest that despite their young age and limited healthcare experience, PA students may already possess a great understanding of professionalism. However, recent literature does not support this finding, as noted above. Another possibility is that the survey itself may be flawed. The wording of many of the questions may indirectly influence students to choose the Much or Great Deal categories, especially as the stated purpose of the survey was to identify qualities that are attributed to professionalism. Key words in the questions may have served as red flags, causing students to select the correct categories. This may explain the great number of responses in the Much and Great Deal categories demonstrated in the presurvey results, thereby rendering the post-survey results as not statistically significant.

\section{Study Limitations}

There are several limitations in the study. First, the survey population was small and not fully representative of the entire PA student population. The student responses to the survey results may not have been accurate. The Likert system used may have confused some students, causing them to reply incorrectly. The length of the survey may have resulted in students rushing through the answers, especially since the same survey was used twice.

(c) The Internet Journal of Allied Health Sciences and Practice, 2016 


\section{Future Recommendations}

As the literature has shown, professionalism education is important in PA education. Unfortunately, the lack of statistical significance found in the study does not support that statement. Several suggestions for the negative results have been discussed in the limitations of the study.

Of course, selecting appropriate students for PA education programs is the first place to start. A certain level of development is necessary. It is also recommended that applicants possess some measure of life experience. Appropriate students are essential to maintain the success of the PA profession. One of the hallmarks of a profession granted by society is self-regulation. A profession that does not regulate itself faces outside interference and possible loss of professional status. ${ }^{18}$

Professionalism education also needs to extend into the clinical arena. The stresses of modern day medicine can result in students seeing suboptimal performance while on clinical rotations. Having students discuss difficult situations in a group setting can result in learning coping mechanisms, rather than passing judgement. Reflective journaling may also provide an effective means of discussing professionalism issues with students. ${ }^{14}$

Establishing an honor code that references a specific code of conduct may be beneficial. An honor code can create an environment that emphasizes academic integrity as an expectation of both faculty and students. Another benefit is to provide guidance to students. It can serve as an aid when determining appropriate responses to unprofessional behavior. ${ }^{19}$

\section{Conclusion}

Despite the lack of statistical significance, student response to the professionalism curriculum and the course itself was overwhelmingly positive as noted above. Students reported they enjoyed the class and learned a lot. It may have been wiser to continue professionalism education throughout the didactic year, incorporating case studies and simulation exercises. Making an argument about the need for professionalism education in PA education is not difficult in light of the challenges and issues that face healthcare providers in the $21^{\text {st }}$ century. In fact, the continued growth and success of the PA profession may be impossible without a solid understanding of professionalism.

\section{REFERENCES}

1. American Academy of Physician Assistants. Physician Assistant Education - Preparation for Excellence, 2014. https://www.aapa.org/workarea/downloadasset.aspx?id=580 Accessed March 13, 2015.

2. Accreditation Review Commission on Education for the Physician Assistant, 2014. http://arcpa.org/documents/Standards4theditionwithclarifyingchanges9.2014\%20FNL.pdf Accessed August 10, 2015.

3. Doscher C. Socialized medicine. PA Professional. February 2011:22-5. http://healthblawg.typead.com/Documents/PA\%20Professional\%2002\%20201.pdf

4. Roe E. Advice on using social media responsibly. How to avoid professional pitfalls. PA Professional. August 6, 2011. Accessed March 18, 2015.

5. American Academy of Physician Assistants. Ethical conduct for the Physician Assistant Profession, 2013. https://www.aapa.org/workarea/downloadasset.aspx?id=815 Accessed August 10, 2015.

6. Hooker RS, Cawley JF. Physician Assistants in Modern Medicine, 2e. St. Louis, MI: Churchill Livingstone, 2003.

7. Papadakis MA, Hodgson CS, Teherani A, Kohatsu ND. Unprofessional behavior in medical school is associated with subsequent disciplinary action by a state medical board. Acad Med. 2004 Mar;79(3):244-249. [PMID: 14985199]

8. Shrank WH, Reed VA, Jernstedt GC. Fostering professionalism in medical education. A call for improved assessments and meaningful incentives. J Gen Intern Med. 2004 Aug;19(8):887-92. [PMID: 15242476]

9. American Board of Internal Medicine Foundation. Medical professionalism in the new millennium: A physician charter. Ann Intern Med. 2002 Feb 5;136(3):243-6. [PMID: 11827500]

10. Ziring D, Danoff D, Grosseman S, Langer D, Esposito A, Jan MK, Rosenzweig S, Novack D. How do medical schools identify and remediate professionalism lapses in medical students? A study of U.S. and Canadian medical schools. Acad Med. 2015 Jul;90(7):913-20. [PMID: 25922920]

11. Blackall GF, Melnick SA, Shoop GH, George J, Lerner SM, Wilson PK, Pees RC, Kreher M. Professionalism in medical education: The development and validation of a survey instrument to assess attitudes toward professionalism. Med Teach. 2007 Mar;29(2-3):e58-62. Doi: 10.1080/01421590601044984. [PMID: 17701611]

12. American Medical Association. American Medical Association's Declaration of Professional Responsibility: Medicine's Social Contract with Humanity, 2001. http://www.cms.org/uploads/Declaration-of-Professional-Responsibility.pdf

13. Freed CR, Franks RD. Medical trainees need more than simple role modeling to be prepared for professional and ethical decisions. Acad Med. 2013 Aug;88(8):1053. [PMID: 23899844]

(C) The Internet Journal of Allied Health Sciences and Practice, 2016 
14. Kalet AL, Sanger J, Chase J, Keller A, Schwartz MD, Fishman ML, Garfall AL, Kitay A. Promoting professionalism through an online professional development portfolio: Success, joys, and frustrations. Acad Med. 2007 Nov;82(11):1065-72. [PMID: 17971693]

15. Humphrey HJ. Medical professionalism: introduction. Perspect Biol Med. 2008 Autumn;51(4):491-4. [PMID: 18997351]

16. Smith ES. The vulnerabilities of social media use and how to survive them. PA Professional. 2012 September:26-8. Accessed August 8, 2015.

17. Herrin B, Ingram T. PHI faux pas: Social media and the unauthorized disclosure of PHI, 2010. http://www.healthlawyers.org/News/HealthLawyersWeekly/Pages?2010/April2010/April30210/PHIFauxPasSocialMediaandt he UnauthorizedDisclosureofPHI.aspx. Accessed March 13, 2015

18. Punkett MJ. Professionalism in physician assistant studies. Perspectives on Physician Assistant Education. 2002;13(1):546.

19. Dereczyk A, Bozimowski G, Thiel L, Higgins R. Physician assistants' attitudes and behaviors toward cheating and academic cheating. J Physician Assist Educ. 2010;21(1):27-31. [PMID: 21141417] 


\section{APPENDIX}

\section{Description}

\section{Professionalism Survey}

The purpose of this Survey is to identify those attributes that are important to YOUR definition of professionalism.

The information you provide is important to help us understand the definition of professionalism as it currently exists here at Nova Southeastern University Orlando PA Program.

The information shared with us will be kept strictly confidential. The maintenance of anonymity is important to us, therefore the questionnaire has not been coded in any way that will link you to your responses.

\section{Instructions}

Circle the answer that describes you for each question in questions 1-5

\section{Question 1}

Gender:

Answer: Male Female

\section{Question 2}

Birth year:

Answer:

\section{Question 3}

Credential:

Answer: B.A. B.S. Ph.D. Other

\section{Question 4}

Citizenship:

Answer: United States Non United States

\section{Question 5}

Previous Health Care Experience:

Answer: Yes No

Carefully read each item statement, keeping in mind how it fits into YOUR definition of professionalism.

Mark the response that best reflects the extent to which you consider each statement in your definition of professionalism in the remaining questions.

Use the scale: Never Little Some Much Great deal 


\section{Question 6}

Maintains patient/physician relationships that do not exploit personal financial gain, privacy, or sexual advantages.

Answer:

1. Never 2. Little 3. Some 4. Much 5. Great Deal

\section{Question 7}

Takes time to review other colleagues' work and provides meaningful and constructive comments to improve it.

Answer:

1. Never 2. Little 3. Some 4. Much 5. Great Deal

\section{Question 8}

Upholds scientific standards and bases decisions on scientific evidence and experience.

Answer:

1. Never 2. Little 3. Some 4. Much 5. Great Deal

\section{Question 9}

Seeks self-improvement

Answer:

1. Never $\quad$ 2. Little $\quad$ 3. Some $\quad$ 4. Much $\quad$ 5. Great Deal

\section{Question 10}

Reports data consistently, accurately and honestly

Answer:

1. Never 2. Little 3. Some 4. Much 5. Great Deal

\section{Question 11}

Avoids offensive speech that offers unkind comments and unfair criticism to others

Answer:

1. Never 2. Little 3. Some 4. Much 5. Great Deal

\section{Question 12}

Shows a willingness to initiate and offer assistance toward a colleague's professional and personal development

Answer:

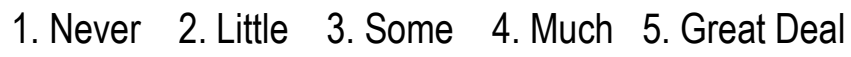

\section{Question 13}

Promotes the welfare and development of associates

Answer:

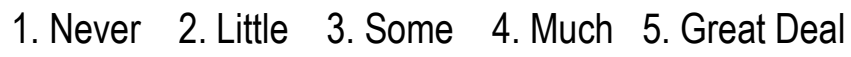

\section{Question 14}

Refuses to violate one's personal and professional code of conduct Answer:
1. Never
2. Little
3. Some
4. Much
5. Great Deal 


\section{Question 15}

Appreciates and respects the diverse nature of patients and honors these differences in one's work with them Answer:

$$
\begin{array}{lll}
\text { 1. Never } \quad \text { 2. Little } \quad \text { 3. Some } \quad \text { 4. Much } \quad \text { 5. Great Deal }
\end{array}
$$

\section{Question 16}

Attends meetings, seminars and presentations as a reflection of support

Answer:

$$
\begin{array}{lll}
\text { 1. Never } \quad \text { 2. Little } \quad 3 . \text { Some } \quad \text { 4. Much } \quad \text { 5. Great Deal }
\end{array}
$$

\section{Question 17}

Works collaboratively and respectfully within a team to the benefit of improved patient care or to the contribution of research

Answer:

$$
\begin{array}{lll}
\text { 1. Never 2. Little } \quad 3 . \text { Some } \quad \text { 4. Much } \quad \text { 5. Great Deal }
\end{array}
$$

\section{Question 18}

Participates in corrective action processes toward those who fail to meet professional standards of conduct Answer:
1. Never
2. Little
3. Some
4. Much
5. Great Deal

\section{Question 19}

Does not seek to advance one's career at the expense of another's career

Answer:
1. Never
2. Little
3. Some
4. Much
5. Great Deal

\section{Question 20}

Volunteers one's skills and expertise for the welfare of the community

Answer:
1. Never
2. Little
3. Some
4. Much
5. Great Deal

\section{Question 21}

Meets commitments and obligations in a timely manner.

Answer:
1. Never
2. Little
3. Some
4. Much 5. Great Deal

\section{Question 22}

Respects the rights, individuality, and diversity of thought of colleagues

Answer:
1. Never
2. Little
3. Some
4. Much 5. Great Deal

\section{Question 23}

Meaningfully contributes to educating fellow colleagues

Answer:
1. Never
2. Little
3. Some
4. Much
5. Great Deal 


\section{Question 24}

Shows compassion

Answer:
1. Never
2. Little
3. Some
4. Much 5. Great Deal

\section{Question 25}

Demonstrates adaptability in responding to changing needs and priorities

Answer:
1. Never
2. Little
3. Some
4. Much
5. Great Deal

\section{Question 26}

Promotes justice in the healthcare delivery system by demonstrating efforts to eliminate discrimination in health care

Answer:

$$
\text { 1. Never 2. Little 3. Some 4. Much 5. Great Deal }
$$

\section{Question 27}

Respects patient autonomy and helps patients make informed decisions

Answer:

$$
\begin{array}{lll}
\text { 1. Never 2. Little } \quad 3 . \text { Some } \quad \text { 4. Much } \quad \text { 5. Great Deal }
\end{array}
$$

\section{Question 28}

Assumes leadership in patient management

Answer:

$$
\begin{array}{lll}
\text { 1. Never 2. Little 3. Some } \quad \text { 4. Much 5. Great Deal }
\end{array}
$$

\section{Question 29}

Recognizes one's own limitations

Answer:

$$
\text { 1. Never 2. Little 3. Some 4. Much 5. Great Deal }
$$

\section{Question 30}

Assumes personal responsibility for decisions regarding patient care Answer:

$$
\begin{array}{lll}
\text { 1. Never 2. Little } & \text { 3. Some } \quad \text { 4. Much } 5 \text {. Great Deal }
\end{array}
$$

\section{Question 31}

Participates in activities aimed at attaining excellence in patient care Answer:

$$
\text { 1. Never 2. Little 3. Some 4. Much 5. Great Deal }
$$

\section{Question 32}

Reports medical or research errors

Answer:
1. Never
2. Little
3. Some
4. Much 5. Great Deal 


\section{Question 33}

Acts in a way that shows a commitment to confidentiality

Answer:
1. Never 2. Little
3. Some
4. Much
5. Great Deal

\section{Question 34}

Adopts uniform and equitable standards for patient care

Answer:
1. Never 2. Little
3. Some
4. Much
5. Great Deal

\section{Question 35}

Commits to implement cost effective patient care

Answer:
1. Never 2. Little
3. Some
4. Much 5. Great Deal

\section{Question 36}

Represents information and actions in a truthful way

Answer:
1. Never 2. Little
3. Some
4. Much 5. Great Deal

\section{Question 37}

Demonstrates empathy

Answer:
1. Never 2. Little
3. Some
4. Much 5. Great Deal

\section{Question 38}

Advocates a patient's interest over one's own interest

Answer:
1. Never
2. Little
3. Some
4. Much 5. Great Deal

\section{Question 39}

Discloses conflicts of interest in the course of professional duties and activities

Answer:
1. Never
2. Little
3. Some
4. Much 5. Great Deal

\section{Question 40}

Is professionally attired in a manner that is respectful of others

Answer:
1. Neve
2. Little
3. Some
4. Much 5. Great Deal

\section{Question 41}

Responds to constructive criticism by working to improve one's capability in the area criticized Answer:
1. Never 2. Little 3. Some 